\title{
The Determinants of Food Prices in Pakistan
}

\author{
Henna Ahsan, ${ }^{*}$ Zainab Iftikhar, ${ }^{* *}$ M. Ali Kemal ${ }^{* * *}$
}

\begin{abstract}
Controlling prices is one of the biggest tasks that macroeconomic policymakers face. The objective of this study is to analyze the demand-and supply-side factors that affect food prices in Pakistan. We analyze their long-run relationship using an autoregressive distributed lag model for the period 19702010. Our results indicate that that the most significant variable affecting food prices in both the long and short run is money supply. We also find that subsidies can help reduce food prices in the long run but that their impact is very small. Increases in world food prices pressurize the domestic market in the absence of imports, which cause domestic food prices to rise. If, however, we import food crops at higher international prices, this can generate imported inflation. The error correction is statistically significant and shows that market forces play an active role in restoring the long-run equilibrium.
\end{abstract}

Keywords: Food prices, ARDL estimation, Pakistan.

JEL Classification: E64, Q11.

\section{Introduction}

For macroeconomic policymakers, price control is one of their biggest tasks, but it is made all the more difficult when food prices rise more than usual, ${ }^{1}$ given the number of external, structural, and demand factors involved in maneuvering food prices. Among others, these factors can include international food prices, subsidies, and the quantity of food crops produced in a particular year and previous years.

According to Trostle (2008), the world market prices of major food items such as vegetable oil and food grains-two essential items used in every household-have increased sharply by more than 60 percent in just two years. Chaudhry and Chaudhry (2008) cite World Bank data that reports an 83 percent increase in food prices during 2005 and 2008. Thus,

* Staff Economist, Pakistan Institute of Development Economics (PIDE), Islamabad, Pakistan.

${ }^{* *}$ Staff Economist, PIDE, Islamabad, Pakistan.

${ }^{* * *}$ Research Economist, PIDE, Islamabad, Pakistan.

${ }^{1}$ The food consumer price index (CPI) constitutes 40 percent of the overall CPI basket (Janjua, 2005). 
the rise in food prices is of great concern for policymakers because it directly affects the poor and below-average-income families, a significant proportion of whose income is spent on food. The authors also find that a 20 percent increase in food prices could lead to an 8 percentage point increase in poverty.

Increased food prices create several problems for the poor, especially in their budget allocations for nonfood items such as health and schooling. According to the United Nations Inter Agency Assessment Mission (2008), the poorest households in Pakistan now need to spend 70 percent or more of their income on food, thus severely compromising their ability to meet essential expenditures on health and education. In turn, there are likely to be more dropouts from school, implying that the country will have a lower chance of achieving its Millennium Development Goal target of 100 percent primary school completion. Similarly, the malnourishment target will also become more difficult to achieve.

Food inflation was very low during 2000-2004, but entered double digits after 2004/05 (see Table 1). The severity of the problem rose when food inflation rose to 23.7 percent in 2008/09-the highest in 23 years. The increase in food prices in Pakistan is generally associated with problems such as the decline in wheat production, increase in international food prices, political economy, and mismanagement by authorities.

Our objective in this article is to identify the determinants of food prices in Pakistan, using (i) the autoregressive distributed lag (ARDL) approach to cointegration, and (ii) different determinants from other studies-Abdullah and Kalim (2011), for example, use the Johansen approach to cointegration and favor the structuralist view that money supply does not have an impact on food inflation, nor do they include world food prices or structural and cyclical variables in their analysis.

The article is organized as follows. Section 2 reviews the determinants of food prices in the context of the subject literature. Section 3 presents our methodology, and Section 4 describes the data and variables used. Section 5 provides an analytical framework, followed by Section 6, which interprets our empirical findings. Section 7 conducts a stability test on the residuals' variance, and Section 8 concludes the study. 
Table 1: Food Inflation in Pakistan

\begin{tabular}{lccc}
\hline Year & Food inflation & Year & Food inflation \\
\hline $1971 / 72$ & 3.39 & $1991 / 92$ & 9.94 \\
$1972 / 73$ & 10.59 & $1992 / 93$ & 11.89 \\
$1973 / 74$ & 34.79 & $1993 / 94$ & 11.34 \\
$1974 / 75$ & 27.80 & $1994 / 95$ & 16.49 \\
$1975 / 76$ & 10.98 & $1995 / 96$ & 10.13 \\
$1976 / 77$ & 12.15 & $1996 / 97$ & 11.90 \\
$1977 / 78$ & 7.82 & $1997 / 98$ & 7.65 \\
$1978 / 79$ & 6.09 & $1998 / 99$ & 6.46 \\
$1979 / 80$ & 8.50 & $1999 / 2000$ & 1.68 \\
$1980 / 81$ & 13.08 & $2000 / 01$ & 3.56 \\
$1981 / 82$ & 13.56 & $2001 / 02$ & 2.50 \\
$1982 / 83$ & 2.75 & $2002 / 03$ & 2.83 \\
$1983 / 84$ & 7.90 & $2003 / 04$ & 6.02 \\
$1984 / 85$ & 5.91 & $2004 / 05$ & 12.48 \\
$1985 / 86$ & 2.58 & $2005 / 06$ & 6.92 \\
$1986 / 87$ & 3.97 & $2006 / 07$ & 10.28 \\
$1987 / 88$ & 8.02 & $2007 / 08$ & 17.64 \\
$1988 / 89$ & 14.15 & $2008 / 09$ & 23.70 \\
$1989 / 90$ & 4.47 & $2009 / 10$ & 12.47 \\
$1990 / 91$ & 12.91 & $2010 / 11$ & 17.35 \\
\hline
\end{tabular}

Note: We have calculated the food CPI, followed by food inflation, using the following formula: $F$ Food Inflation $=\frac{\text { Food } C P I_{t}-\text { Food } C P I_{t-1}}{\text { Food } C P I_{t-1}} \times 100$

Source: Government of Pakistan. Pakistan economic survey for 1971/72 to 2010/11.

\section{Determinants of Food Prices: A Literature Review}

Several studies have examined the determinants of food prices, especially after the latter's recent increase. The first major food price hike occurred in 1973. In this context, Eckstein and Heien (1978) identify a number of factors that accounted for food inflation in the US in 1973, including monetary policy, actions by both the US and foreign governments, the Soviet grain deal, world economic conditions, devaluation of the US dollar, and rapid income growth as the American economy moved out of a recession. Lamm and Westcott (1981) find that increased factor prices affect food prices and, moreover, that increased farm-level prices and substantial 
rises in nonfarm resource prices appear to explain why food prices were affected more than nonfood prices in the 1970s.

Lapp's (1990) results show that variations in the growth rate of money supply-either anticipated or unanticipated-did not affect the average price level received by farmers relative to other prices in the economy during 1951-85. The positive impact of unexpected money growth on the relative prices of agricultural commodities is significant only for a short period. His findings show that the estimated effect is quantitatively small and that, economically, there is no significant variation in the relative prices of agricultural commodities.

Khan and Qasim (1996) conclude that food inflation is driven by money supply, value-added in manufacturing, the wheat support price, and the price of utilities. Nonfood inflation is determined by money supply, real gross domestic product (GDP), import prices, and electricity prices. It is not surprising that changes in the wheat support price should affect the food price index, given that wheat products account for 14 percent of the index. Using ordinary least squares, Khan and Gill (2007) analyze the impact of money on both food and general price indices for the period 1975-2007. They emphasize the comparison between the food CPI and overall CPI, and find that M1 is more strongly associated with the overall CPI than with the food CPI.

The Asian Development Bank (ADB)'s (2008) study addresses three sets of factors that are underscored as the main causes of high food prices in developing Asia. The first is the distinction between supply and demand, the second is the distinction between structural and cyclical factors, and the third is the relationship between international and domestic markets. The structural factors identified are the fall in production growth below consumption growth over several years. Rice and wheat stocks have ebbed and are now about 200 million metric tons, compared with 350 million metric tons in 2000-a decline of about 43 percent (United States Department of Agriculture, 2008).

One of the most important demand factors that influence food prices is the change in dietary habits of people in emerging market economies due to an increase in their income (ADB, 2008). People with higher incomes have now shifted to meat and dairy products, which requires that large amounts of grain be fed to livestock and causes a decline in grain production for human consumption. The other major policyrelated factor that has affected food prices is the competing use of food 
grain to produce ethanol as a substitute for oil. Bio-fuel demand has also risen and led to the diversion of grains, soybeans, sugar, and vegetable oil from use as food or feed (ADB, 2008).

Capehart and Richardson (2008) argue that higher commodity and energy costs are key determinants of higher food prices in the US. Similar to the ADB's (2008) study, they address issues of rapidly changing consumption patterns, i.e., greater demand for processed foods and meat in countries such as China and India, which require more food grains and edible oil, leads to reduced stocks of corn, wheat, and soybeans at the world level and increases food prices. The study also identifies some important supply-side determinants, such as urbanization and the competing demand for land for commercial-as opposed to agriculturalpurposes. Moreover, the neglect of investment in agricultural technology, infrastructure, and extension programs is also to blame for the lack of rapid growth in the supply of rice (International Rice Research Institute, 2008).

Gómez (2008) finds that the inflation and exchange rates in China and India are significant in explaining food inflation in Colombia. He points out, however, that the recent increase in food inflation in Colombia in 2007 was also due to drought and expansionary monetary policy, but that its effect was only short-term. The change in consumption habits due to the country's rise in per capita income has increased the demand for meat relative to the demand for cereals, and led to food inflation. Increasing agricultural growth would reduce food inflation and benefit poorer countries.

Naim (2008) argues that factors that may account for the recent inflation include rising energy prices, nonfood hedging policies against drought years, speculation in food commodity markets, and the US's corn ethanol policy. Trostle (2008) examines the rising world market prices of food commodities, and points out that some factors reflect slower growth in production and more rapid growth in demand, which increases food prices. Recent factors that have affected food prices include global demand for bio-fuel feed stock and adverse weather conditions in 2006 and 2007. Other factors that have also led to food inflation include the decline in the value of the US dollar, rising energy prices, the increasing agricultural cost of production, growing foreign exchange holdings by major food-importing countries, and recent policies adopted by some exporting and importing countries. 
Among recent studies on Pakistan, Mushtaq, Ghafoor, Abedullah, and Ahmad (2011) show that the real money supply, real exchange rate, and openness affect wheat prices in the long run. Abdullah and Kalim (2011), however, argue that money supply does not determine food prices, and that factors such as per capita GDP, food imports and exports, and support prices determine food prices instead.

\section{Methodology}

In this section, we formulate a framework within which to determine the various factors that may, potentially, affect food inflation in Pakistan. We know that inflation is necessarily a monetary phenomenon in the long run (see Haque \& Qayyum, 2006; Kemal, 2006). Khan and Qasim (1996) find that money supply is one of the major causes of food inflation in Pakistan, while Abdullah and Kalim (2011) argue that it is an insignificant factor. Other than money supply, demand and supply factors, cyclical and structural factors, and international and domestic shocks are crucial in explaining increases in food prices.

We start with a simple microeconomic demand-and-supply framework from which to derive an equilibrium price. We then add to this model other cyclical and structural variables and international price variables. Demand-side factors that affect the quantity demanded of food include the price of food, income, and money demand.

$$
Q_{d}^{F}=\alpha_{0}+\alpha_{1} F P+\alpha_{2} P C I+\alpha_{3} M S+u_{d}
$$

FP represents the prices of food items, which affect demand negatively; PCI represents per capita income, which is positively associated with food demand; MS represents money supply, used as a proxy for money demand with an equality constraint (i.e., $M S=M D$ ), which is positively associated with the demand for food; and $u_{d}$ is the error term.

Supply-side factors that affect the quantity supplied of food include food prices, subsidies, energy prices, and domestic production.

$$
Q_{s}^{F}=\beta_{0}+\beta_{1} F P+\beta_{2} S U B+\beta_{3} Y+\beta_{4} \text { Energy Prices }+u_{s}
$$

We expect to find a positive association between quantity supplied and food prices $(F P)$. SUB represents subsidies to the agricultural sector, which is positively associated with quantity supplied; $Y$ is the output of food items per year in the country, which is positively associated with quantity of 
food supplied. Energy prices affect supply in two ways: (i) through a decline in production, which is covered in the domestic production variable, and (ii) through transportation costs. Finally, $u_{s}$ is the error term.

In this framework, the prices of food items are determined at equilibrium when the quantity of food items demanded is equal to the quantity supplied:

$$
\begin{aligned}
& Q_{d}^{F}=Q_{s}^{F} \Rightarrow \\
& \alpha_{0}+\alpha_{1} F P+\alpha_{2} P C I+\alpha_{3} M S+u_{d}=\beta_{0}+\beta_{1} F P+\beta_{2} S U B+\beta_{3} B I+\beta_{4} Y+\beta_{5} \text { Energy Prices }+u_{s}
\end{aligned}
$$

After rearranging, this yields

$$
\begin{aligned}
& F P=\gamma_{0}+\gamma_{1} P C I+\gamma_{2} M S+\gamma_{4} S U B+\gamma_{4} Y+\gamma_{5} B I+\gamma_{6} \text { Energy Prices }+v \\
& \gamma_{0}=\frac{\beta_{0}-\alpha_{0}}{\alpha_{1}-\beta_{1}}, \gamma_{1}=\frac{-\alpha_{2}}{\alpha_{1}-\beta_{1}}, \quad \gamma_{2}=\frac{-\alpha_{3}}{\alpha_{1}-\beta_{1}}, \gamma_{3}=\frac{\beta_{2}}{\alpha_{1}-\beta_{1}}, \gamma_{4}=\frac{\beta_{3}}{\alpha_{1}-\beta_{1}}, \\
& \gamma_{5}=\frac{\beta_{4}}{\alpha_{1}-\beta_{1}}, \quad \gamma_{6}=\frac{\beta_{5}}{\alpha_{1}-\beta_{1}}, \quad v=\frac{u_{s}-u_{d}}{\alpha_{1}-\beta_{1}}
\end{aligned}
$$

Equation (3) derives equilibrium food prices from the demand and supply framework. $Y$, agricultural output, is treated as a structural and cyclical determinant of food prices. It indicates the impact of current production on food prices, which, over time, increases or declines. What remain missing, however, are international food prices. These are incorporated in Equation (4), which gives all the variables in natural log form.

$$
\begin{aligned}
& \log (F P)=\gamma_{0}+\gamma_{1} \log (P C I)+\gamma_{2} \log (M S)+\gamma_{4} \log (S U B)+\gamma_{5} \log (Y)+ \\
& \gamma_{6} \log (B I)+\gamma_{7} \log (\text { Energy Prices })+\gamma_{8} \log (W F P)+v
\end{aligned}
$$

\section{Data and Variables}

\subsection{Sources of Data}

Data on the food CPI, per capita income, population, and money supply has been drawn from the Government of Pakistan's (n.d.) Pakistan economic survey. Data on agricultural subsidies is from the Government of Pakistan's (n.d.) Federal budget: Budget in brief, while that on food crop production is from the Agricultural statistics of Pakistan (Government of Pakistan, n.d.). Data on bureaucratic efficiency has been taken from the 
Political Risk Services Group (n.d.), and data on world food prices from the International Monetary Fund Statistics Department (2008). The annual data for all variables is for the period 1970-2010, apart from world food prices, which is available up to 2008. All the variables used are in natural log form, which gives direct elasticities.

\subsection{Description of Variables}

This section looks at the expected signs of the variables shown in Equation (4).

\subsubsection{Per Capita Income (PCI)}

We include PCI as a demand-side determinant of food inflation, using it as a proxy for the country's dietary habits. A higher PCI leads to higher consumption of food as well as a change in dietary habits, e.g., the increased consumption of meat and dairy products over that of cereals. This requires a large amount of grain feed for livestock and, so, causes a decline in the production of grain for human consumption. Hence, the food price of grain for human consumption increases since it is now more valuable. Thus, we expect to find per capita income to be positively associated with food prices.

\subsubsection{Money Supply (MS)}

Money supply is a proxy for money demand through the equality constraint $M S=M D$ because people demand more money to spend on consumption. Thus, when more money is demanded for consumption on food, then food prices go up. The higher the money demand, the higher will be the money supply, and the higher the food prices. Thus, money supply is positively associated with food prices.

\subsubsection{Agricultural Subsidy (SUB)}

An agricultural subsidy is a supply-side determinant that can affect food prices in two different ways: (i) it can reduce the cost of production and, hence, decrease food prices; or (ii) it can provide a support price for wheat and other crops to stabilize their prices, giving farmers confidence that they will get at least that amount even if the market price goes down. The subsidy causes suppliers to increase their production, and creates a larger supply in the market, reducing the market price. In both cases, the agricultural subsidy is negatively associated with food prices. 


\subsubsection{Agricultural Output (Y)}

Food crops are taken as an agricultural output, which is a structural and cyclical variable in the long run, representing the output of food items. This variable represents, over time, changes in the production and cyclical movement of food items. The upper part of Figure 1 shows the very irregular movement of agricultural output per capita, while the lower part shows food crop amounts measured in thousands of tons.

Figure 1: Agricultural Output per Capita and Food Crops
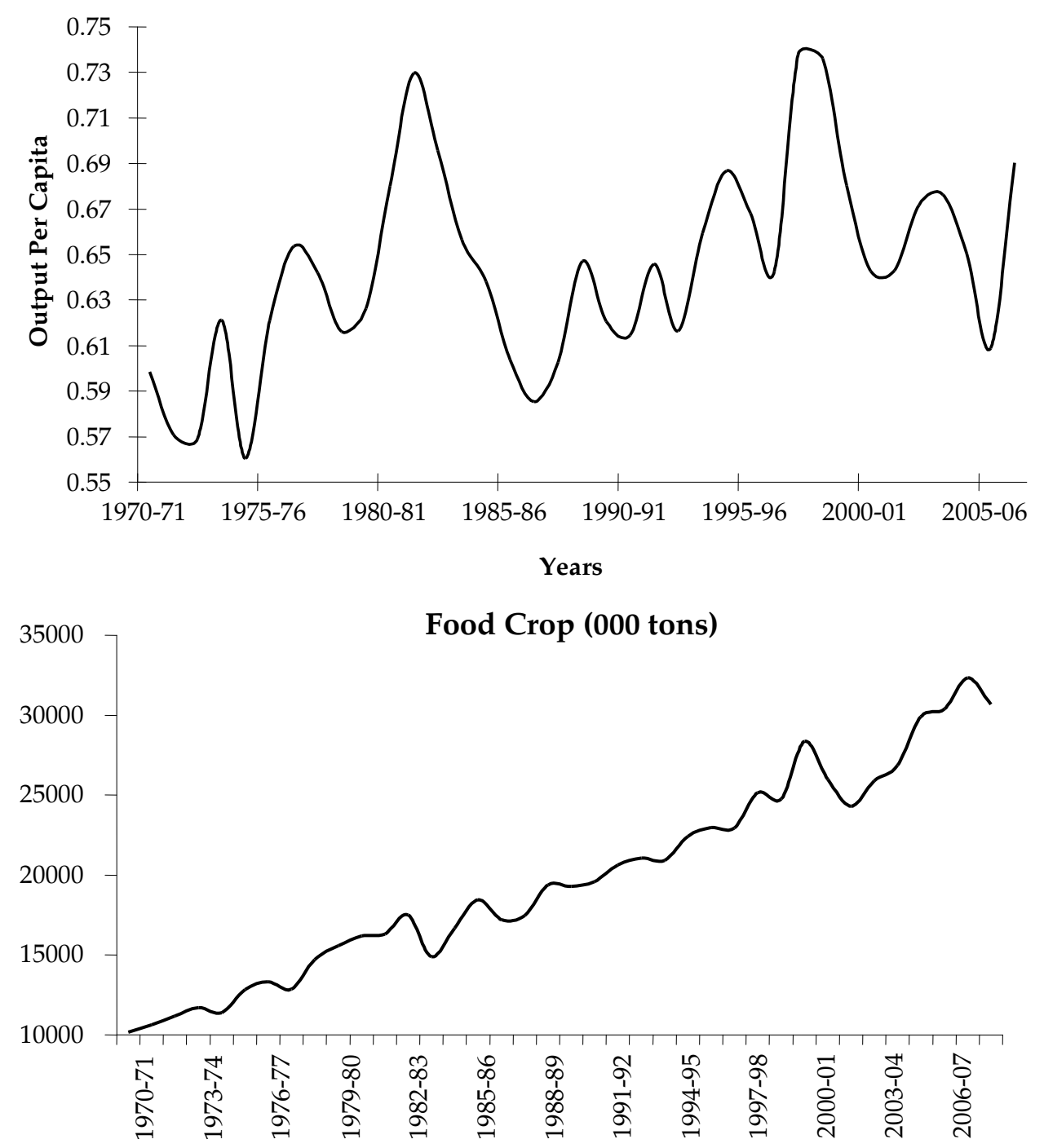

Source: Government of Pakistan. Agricultural statistics of Pakistan for 1970/71 to 2006/07. 
The lower availability of food crops has two outcomes: (i) excess demand, and (ii) it makes things more valuable. In both cases, the prices of food crops go up. Thus, we expect to find a negative association between food crops and food prices.

\subsubsection{World Food Prices (WFP)}

World food prices are the third type of determinant of food prices discussed by the ADB (2008). They show the interlinkage between domestic and international markets. An increase in international prices can impact domestic prices (i) by putting pressure on the domestic market, because exporters may legally or illegally export those commodities; or (ii) through the import of food crops if there is a deficiency of those products in the country. In both cases, world food prices are positively associated with domestic food prices.

\subsection{Descriptive Analysis of Data}

Figure 2 shows the subsidy-output ratio and annual food inflation. Overall, the movement in the two variables is ambiguous but there are periods of positive and negative association. However, in the late 1990s, the decline in subsidies is matched by a decline in prices, which is surprising. A 33 percent correlation between the two variables is too low to explain any association between the variables.

\section{Figure 2: Subsidy-Output Ratio and Annual Food Inflation}
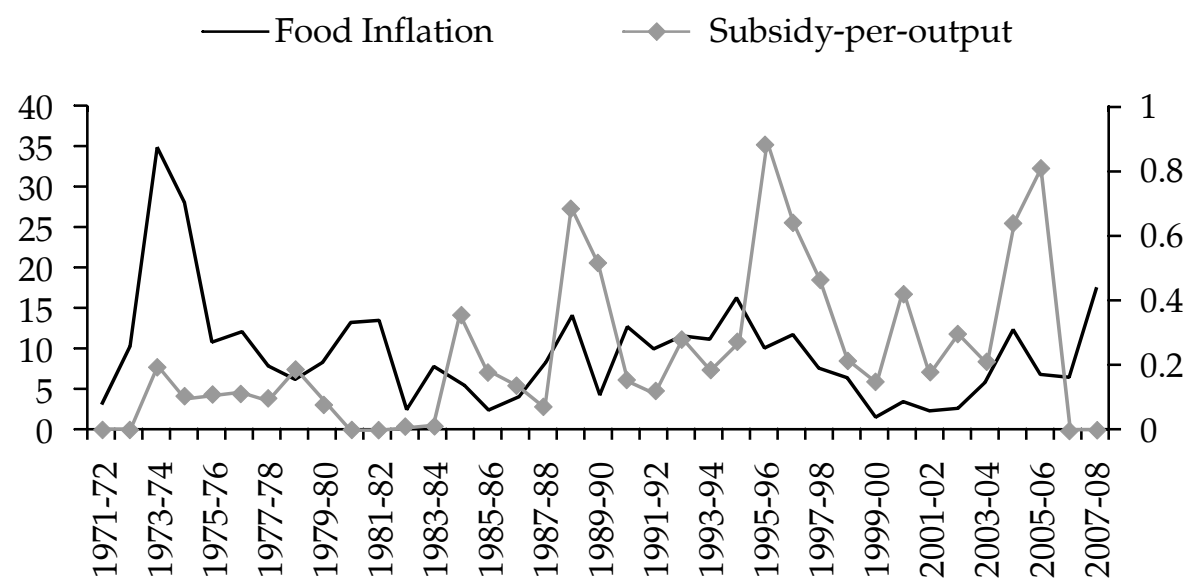

Source: Authors' estimates based on data from Government of Pakistan, Federal budget: Budget in brief and Pakistan economic survey for 1971/72 to 2007/08. 
Figure 3 shows a significant, positive, long-run association between per capita income and food prices. However, if we look carefully at the graph, we can see a negative association in certain periods. Apart from in 1995 and 2003, food prices grow at an increasing rate while per capita income rises at a decreasing rate up until early 2000, after which it increases at a constant rate. Correlation between the two variables is very high at 93.35 percent, which shows that their relationship is significant. Interestingly, however, correlation between food inflation and per capita income growth is -4 percent, which is both very low and negative.

\section{Figure 3: Per Capita Income and Growth Relative to Food Prices and Inflation}
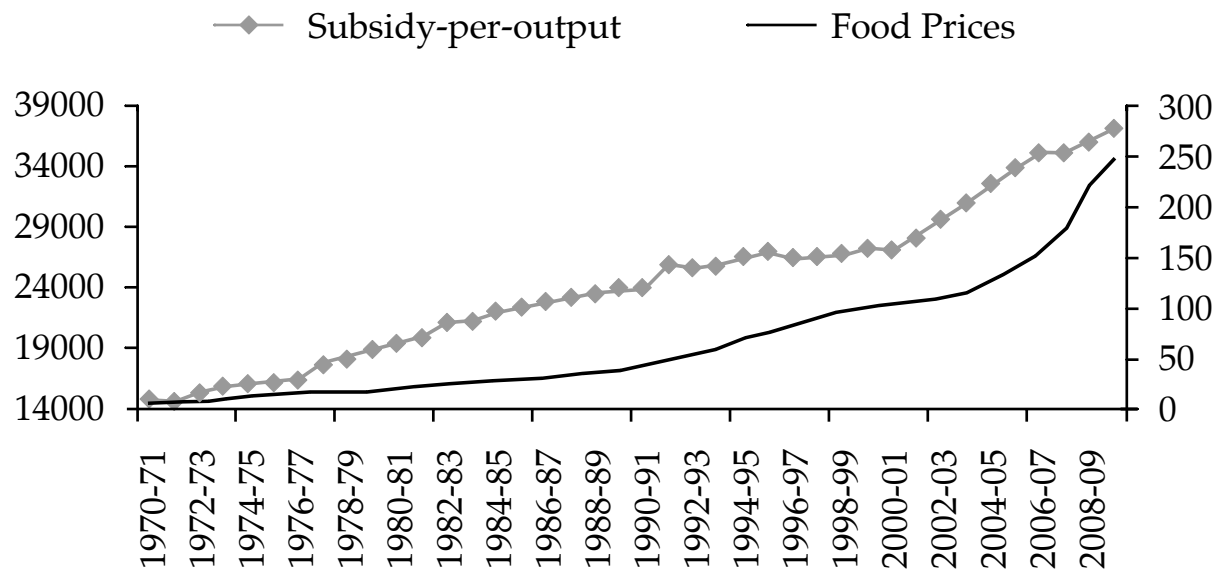

$\rightarrow-$ Per Capita Growth $\quad \rightarrow$ Food Inflation
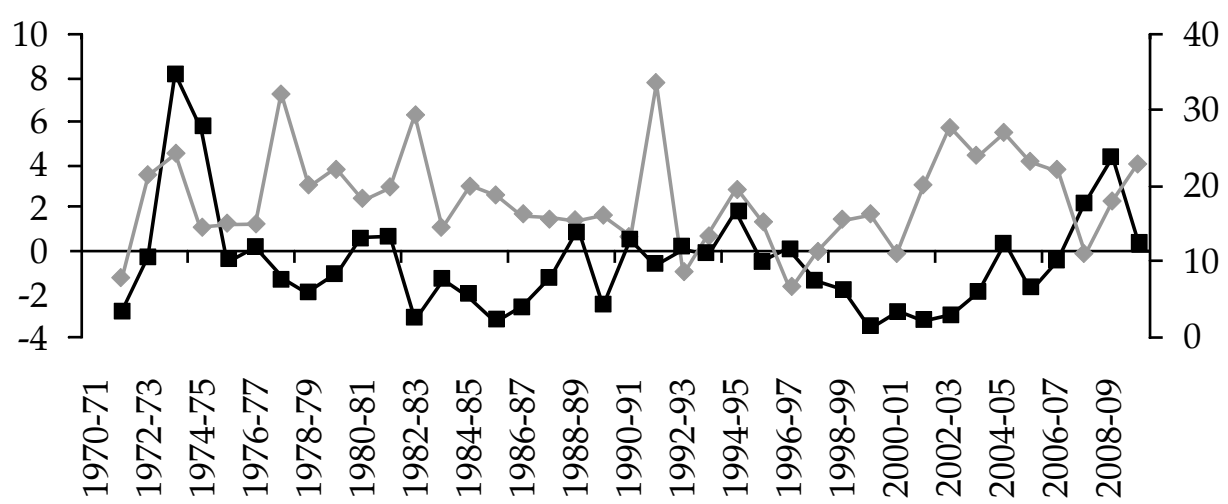

Source: Authors' estimates based on data from Government of Pakistan, Pakistan economic survey for $1970 / 71$ to $2008 / 09$. 
Figure 4 shows that there is a strong, positive relationship between money supply and food prices in the long run. However, the bottom figure indicates that money growth has a lagged impact on food inflation in the short run. Correlation between the two variables is considerably high at 97 percent. Correlation between money growth and food inflation with a oneperiod lag is 23 percent, which is positive but not very high.

\section{Figure 4: Food Prices and Inflation Relative to Money Supply and Growth}

\section{-----. Food Prices — Money Supply}
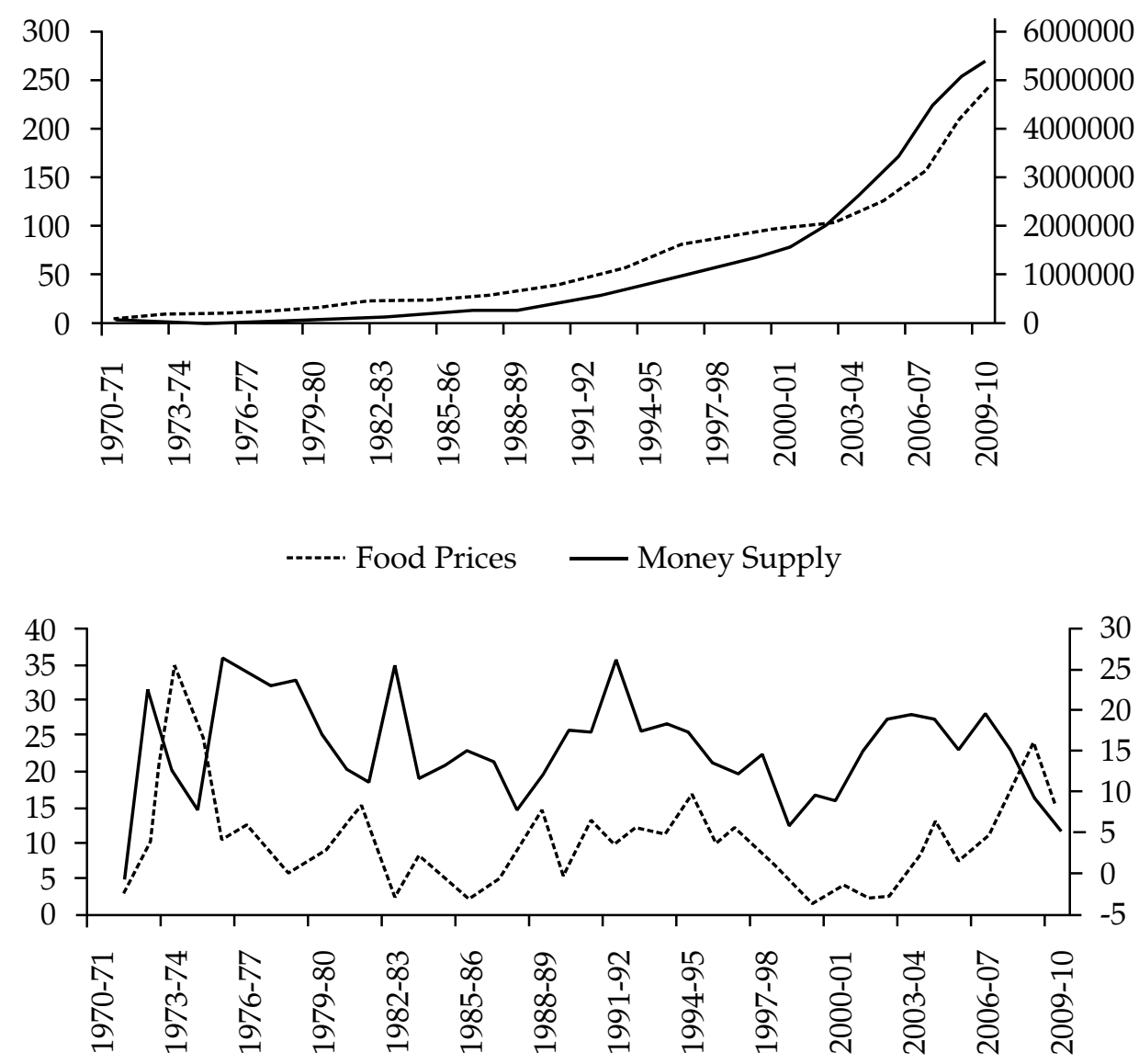

Source: Authors' estimates based on data from Government of Pakistan, Pakistan economic survey for $1970 / 71$ to $2009 / 10$.

Figure 5 shows food crop movements relative to food prices, and growth in food crop movements relative to food inflation. Food crops show fairly irregular movements while food prices do not respond to this 
movement as such. The bottom figure depicts random walk behavior by food crop growth, which is not matched by the movements in food inflation.

\section{Figure 5: Food Crop Movement and Growth Relative to Food Prices and Inflation}

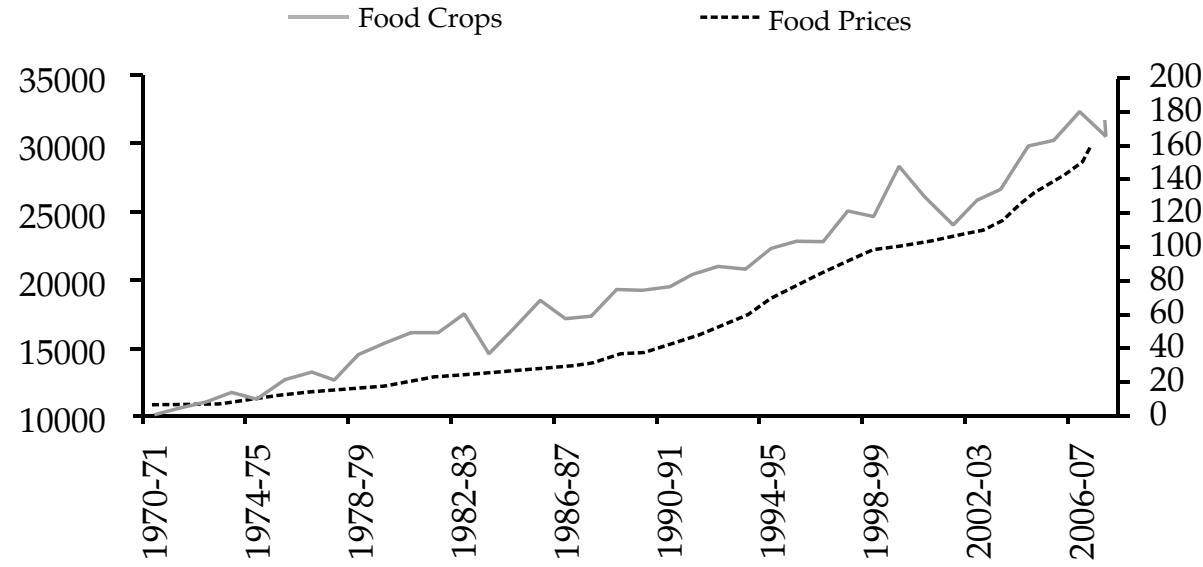

— Food Crops-Growth — Food Inflation

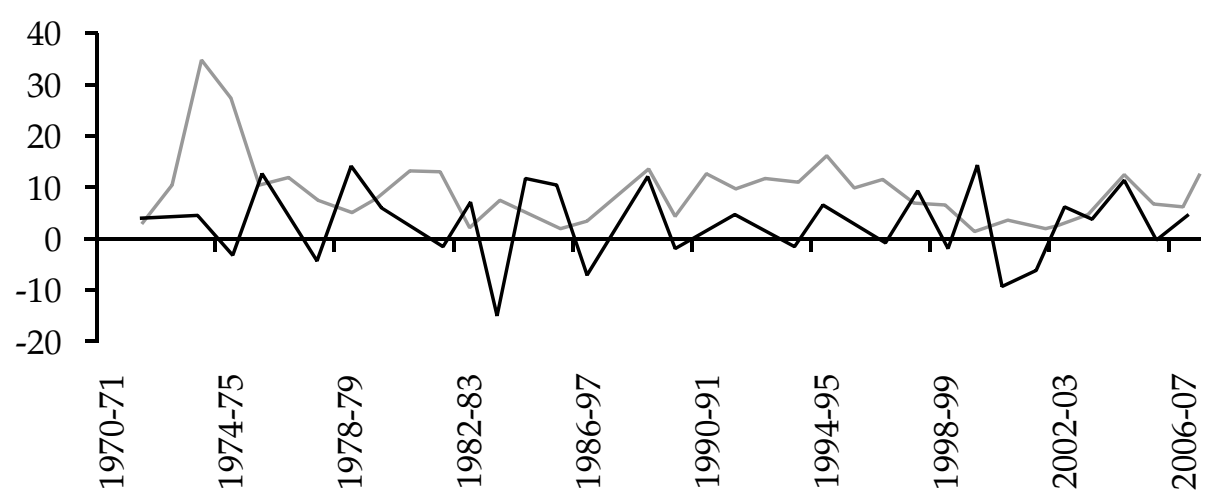

Source: Authors' estimates based on data from Government of Pakistan, Agricultural statistics of Pakistan and Pakistan economic survey for 1970/71 to 2008/09.

Figure 6 presents an ambiguous relationship between domestic food prices and world food prices, although the series has followed the same trend and has had a significant association over time since 1998/99. The figure shows that domestic inflation responds to world food inflation with a period lag-the correlation between the two variables with a oneperiod lag is 74 percent. This implies that the two variables are clearly associated with one another. 
Figure 6: Movement of Domestic and World Food Prices and Inflation

-World Food Prices — Food Prices

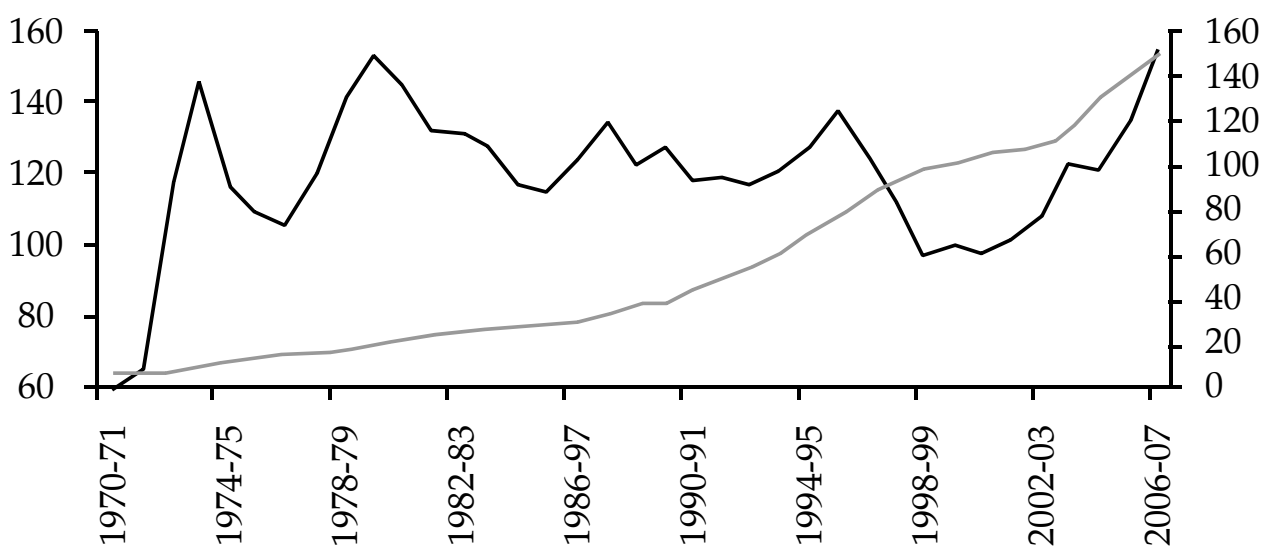

—World Food Inflation — Food Inflation

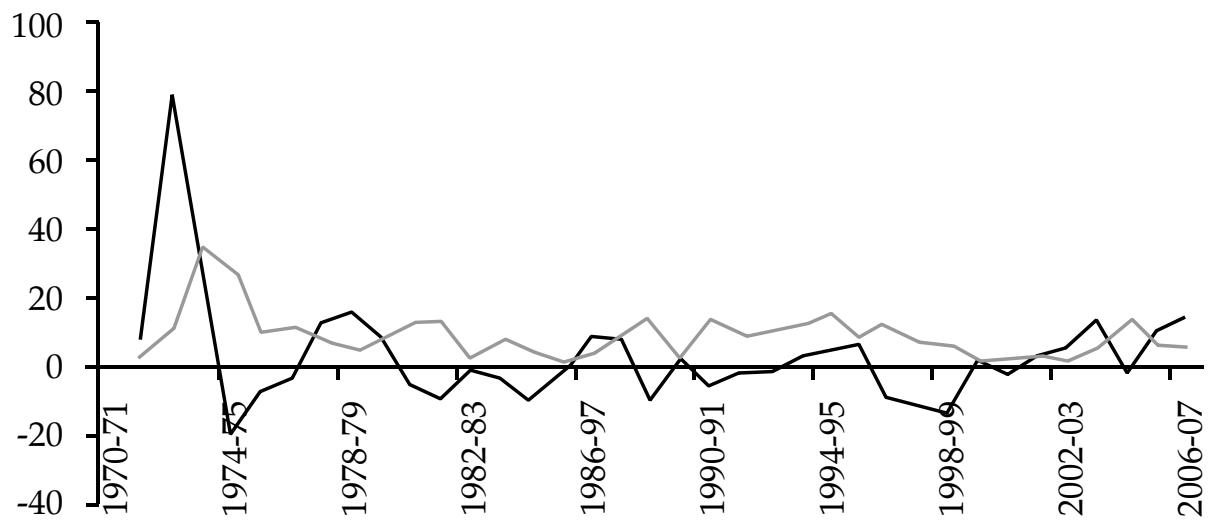

Source: Authors' estimates based on data from International Monetary Fund Statistics Department and Government of Pakistan, Pakistan economic survey for 1970/71 to 2006/07.

\section{Analytical Framework}

Since we are interested in examining the determinants of food prices in both the long- and short run, we will use a cointegration analysis. There are several techniques available for this, including the Johansen approach, Engle-Granger approach, and ARDL approach, but each starts in almost the same way: If the variables are integrated of the same order and their linear combination is integrated of an order less than the order of the variables, it implies that there is cointegration among the variables. However, more recent approaches, such as that of the ARDL model, also allow variables of different orders of integration. 


\subsection{Unit Root Test}

We apply the augmented Dickey-Fuller (ADF) test-using both a constant and trend, and lagged differences of the logs of all the variablesto check the unit root of the series. If the series has a unit root, i.e., if it is not stationary in levels, this implies that the series is nonstationary. We then check the series in first differences using both the constant and trend and appropriated lagged differences. If the series remains nonstationary, we take the second difference of the variable; this process continues until we obtain the desired results. However, if it is stationary in first differences, we stop there. Lagged differences are an essential part of the ADF test, which help avoid the problem of serial correlation. The optimal lag levels are chosen using the minimum Akaike information criterion (AIC). The specifications for the ADF tests are

$$
\begin{aligned}
& \log \left(\mathrm{y}_{\mathrm{t}}\right)=\rho \log \left(y_{t-i}\right)+\gamma \sum_{i=1}^{n} \Delta \log \left(y_{t-i}\right) \\
& \log \left(\mathrm{y}_{\mathrm{t}}\right)=\alpha+\rho \log \left(y_{t-i}\right)+\gamma \sum_{i=1}^{n} \Delta \log \left(y_{t-i}\right) \\
& \log \left(\mathrm{y}_{\mathrm{t}}\right)=\alpha+\beta t+\rho \log \left(y_{t-i}\right)+\gamma \sum_{i=1}^{n} \Delta \log \left(y_{t-i}\right) \\
& \Delta \log \left(\mathrm{y}_{\mathrm{t}}\right)=\delta \log \left(y_{t-i}\right)+\gamma \sum_{i=1}^{n} \Delta \log \left(y_{t-i}\right)
\end{aligned}
$$

where $y$ is any variable, $t$ is the trend variable, $\rho$ is the autocorrelation coefficient, $\alpha$ and $\beta$ are parameters, $\varepsilon$ is the error term, and subscript $t$ represents time periods. However, we run the ADF test in difference form, and thus Equations (5), (6), and (7) become

$$
\begin{aligned}
& \Delta \log \left(\mathrm{y}_{\mathrm{t}}\right)=\alpha+\delta \log \left(y_{t-i}\right)+\gamma \sum_{i=1}^{n} \Delta \log \left(y_{t-i}\right) \\
& \Delta \log \left(\mathrm{y}_{\mathrm{t}}\right)=\alpha+\beta t+\delta \log \left(y_{t-i}\right)+\gamma \sum_{i=1}^{n} \Delta \log \left(y_{t-i}\right)
\end{aligned}
$$

Thus, the stationarity test is applied to three autoregressive processes: (i) of order one with no intercept or trend, (ii) with an intercept 
but no trend, and (iii) with both an intercept and trend. We check the lagged differences using the minimum AIC or Schwarz's Bayesian criterion (SBC). ${ }^{2}$ Our one-tailed null hypothesis is

$$
\begin{array}{lll}
H_{o}=\rho \geq 1 & \text { or } & \delta \geq 0 \\
H_{A}=\rho<1 & \text { or } & \delta<0
\end{array}
$$

If $\mathrm{H}_{\mathrm{o}}$ is rejected, the series has no unit root and is, therefore, stationary. If $\mathrm{H}_{\mathrm{o}}$ is not rejected, we conclude that there is a unit root in the series and that it is nonstationary. The test is initially applied in levels; if the level is nonstationary, the test is then applied in first differences. If the first difference is also nonstationary, the test is applied in second differences, and so on.

Other approaches to checking for unit roots in the data include the Phillips-Perron (PP) test and Kwiatkowski-Phillips-Schmidt-Shin (KPSS) (1992) test. The PP test determines stationarity in the presence of structural breaks in the data. Its null hypothesis is the same as that of the ADF test, i.e., that there is a unit root in the series. Unlike the ADF and PP test, however, the KPSS test's null hypothesis is that there is no unit root in the series. Thus, if the null hypothesis is accepted, then the series is considered stationary. We apply all three tests to our data to avoid any bias.

\subsection{Cointegration}

Of the various approaches to cointegration, the most popular are the Engle-Granger single-equation, two-step, approach; the multipleequation Johansen approach; and the ARDL single-equation approach. Since our objective is to determine the long-run determinants of food prices, we do not use the Johansen approach, which is better suited to multiple cointegrating vectors. ${ }^{3}$ The Engle-Granger approach has certain shortcomings, which are mostly overcome by Pesaran and Shin's (1997) ARDL approach (see also M. A. Khan, Qayyum, \& Sheikh, 2005). The ARDL approach yields consistent estimates of the long-run coefficients irrespective of the order of integration of the variables, i.e., whether they are integrated of order one, I(1) or zero, I(0) (Pesaran \& Shin, 1997).

\footnotetext{
${ }^{2}$ The AIC is preferable to other approaches to lag selection, especially when the sample size is smaller than 60 (Liew, 2004).

${ }^{3}$ It is not necessary to check for multiple cointegrating vectors, since this is not our objective.
} 
We estimate the long-run equation as follows, and use the F-statistic to check the significance of the variables in lagged level form jointly, i.e., where $\mathrm{H}_{\mathrm{o}}$ is $\beta_{1}=\beta_{2}=0$. If the F-statistic is significant, we can assume that there is a long-run relationship between the variables.

ARDL Representation (Two-Variables Case)

$$
\Delta y_{t}=\beta_{0}+\beta_{1} y_{t-1}+\beta_{2} x_{t-1}+\sum_{i=1}^{n} \beta_{3} \Delta y_{t-i}+\sum_{i=1}^{n} \beta_{4} \Delta x_{t-i}+\varepsilon_{t}
$$

The number of lagged differences is determined using either the AIC or SBC. This can be checked using a general-to-specific (GTS) methodology, i.e., by checking the significance of all the differenced variables jointly at each lag. For example, if we regress the equation including four lags (lagged differences) for each variable, check all the terms of lag four jointly using the F-statistic, and find that it is insignificant, then we would have to regress the equation once again using three lags, and continue this process until it yielded statistically significant results. After the final estimation, we check the joint significance of the lagged variables. In this equation, it is $\beta_{1}=\beta_{2}=0$. If it is significantly different from 0 , then this implies that there is a long-run relationship among the variables.

Checking the unit root of the residuals is one of the major steps of cointegration. Residuals should be integrated of order zero. To obtain the residuals, we use the equation $\hat{\varepsilon}_{t}=\beta_{1} y_{t-1}+\beta_{2} x_{t-1}$ and then apply the ADF, PP, and KPSS test, to check their stationarity. Following this, we move on to the error correction equation, which indicates the adjustment behavior of the dependent variable if it should deviate from the equilibrium path.

\section{Empirical Results}

Table 2 presents the results of the three unit root tests. In addition to the ADF test, we have applied the PP test, which is used when there are structural breaks in the series-a very common occurrence in economic policy variables such as subsidies if they are not consistent every year. The KPSS test has a null hypothesis that is opposite to the ADF and PP tests, and states that the series is stationary. This is a Lagrange multiplier test, which assumes that the random walk has a zero variance. 
The results of the stationarity tests show that food prices, money supply, per capita income, and food crops are nonstationary variables but are integrated of order one, i.e., they are stationary in first differences. However, subsidies and world food prices are level stationary. Apart from the subsidy variable, all three tests yield the same results. Since both the ADF and PP tests give the same results for the subsidy variable-i.e., indicate that it is stationary-we also conclude that it is stationary.

Table 2: Results of Stationarity

\begin{tabular}{lllllll}
\hline & \multicolumn{9}{c}{ ADF } & & \\
\cline { 2 - 5 } \multicolumn{1}{c}{ Variable } & \multicolumn{7}{c}{ Constant + trend } & \multicolumn{2}{c}{ Constant } & KPSS & PP \\
\hline Ln (food prices) & $-4.27^{*}$ & $(10)$ & -0.43 & $(11)$ & $-0.78^{*}$ & -0.88 \\
$\Delta$ Ln (food prices) & $-4.22^{*}$ & $(10)$ & $-4.51^{*}$ & $(10)$ & 0.13 & $-3.58^{* *}$ \\
Ln (money supply) & -2.26 & $(2)$ & -2.75 & $(12)$ & $0.78^{*}$ & -0.85 \\
$\Delta$ Ln (money supply) & $-4.13^{* *}$ & $(7)$ & $-3.29^{* *}$ & $(4)$ & 0.11 & $-5.31^{*}$ \\
Ln (PCI) & -1.90 & $(1)$ & -0.69 & $(1)$ & $0.77^{*}$ & -0.16 \\
$\Delta$ Ln (PCI) & $-3.98^{* *}$ & $(1)$ & $-4.01^{* *}$ & $(1)$ & 0.10 & -5.87 \\
Ln (food crops) & -3.51 & $(1)$ & -1.14 & $(8)$ & $0.73^{*}$ & -0.87 \\
$\Delta$ Ln (food crops) & $-6.73^{*}$ & $(1)$ & $-6.81^{*}$ & $(1)$ & 0.05 & $-9.39^{*}$ \\
Ln (subsidy) & $-4.75^{*}$ & $(1)$ & $-4.01^{*}$ & $(1)$ & $0.79^{*}$ & $-8.24^{*}$ \\
Ln (world food prices) & $-6.40^{*}$ & $(1)$ & $-6.43^{*}$ & $(1)$ & 0.18 & $-4.08^{*}$ \\
\hline
\end{tabular}

Note: Asterisks * and ${ }^{* *}$ indicate significance at 1 and 5 percent, respectively. Lagged differences are given in parentheses.

Source: Authors' estimates.

Equation (4) was given in log linear form. We have used all the variables and can now estimate Equation (12), which represents the ARDL approach to cointegration.

$$
\begin{aligned}
\Delta f p_{t}= & \beta_{0}+\beta_{1} f p_{t-1}+\beta_{2} S U B_{t-1}+\beta_{3} P C I_{t-1}+\beta_{4} Y_{t-1}+\beta_{5} m s_{t-1}+\beta_{6} w f p_{t-1}+\sum_{i=1}^{n} \beta_{7} \Delta f p_{t-i} \\
& +\sum_{i=1}^{n} \beta_{8} \Delta S U B_{t-i}+\sum_{i=1}^{n} \beta_{9} \Delta P C I_{t-i}+\sum_{i=1}^{n} \beta_{10} \Delta Y_{t-i}+\sum_{i=1}^{n} \beta_{11} \Delta m s_{t-i}+\sum_{i=1}^{n} \beta_{12} \Delta w f p_{t-i}+\varepsilon_{t}
\end{aligned}
$$

Equation (12) represents the ARDL model of the estimated equation. All the variables are in log form: $F P$ is the log of food prices, SUB is the subsidy in log form, $P C I$ is the log of real per capita income, FC is the log of food crops, MS is the log of money supply, WFP is the log of world food prices, and $\varepsilon_{1 t}$ is the error term of Equation (9). Subscript $t$ represents 
the time period, the $\beta$ terms are the coefficients of each variable, and $n$ represents the number of lags.

The minimum AIC indicate the number of lagged differences as being three. After estimating the entire equation with all the variables at three lag levels, we find that there are several insignificant variables affecting the significance of other variables as well. The model allows us to estimate the general model first, and the specific model second, and so is known as a GTS model. The results of the specific ARDL model are given in Table 3.4 The diagnostic tests for the ARDL model indicate that neither serial correlation (Lagrange multiplier test) nor heteroscedasticity (BreuschPagan-Godfrey) are problems.

Table 3: Results of ARDL Equation

\begin{tabular}{lccc}
\hline Variable & Coefficient & t-statistic & Prob. \\
\hline $\mathrm{D}(\mathrm{SUB}(-1))$ & 0.015 & $2.13^{* *}$ & 0.0478 \\
$\mathrm{D}(\mathrm{PCI}(-2))$ & -0.934 & $-3.22^{*}$ & 0.0050 \\
$\mathrm{D}(\mathrm{FP}(-3))$ & 0.602 & $5.45^{*}$ & 0.0000 \\
$\mathrm{D}(\mathrm{SUB}(-3))$ & -0.008 & $-2.67^{* *}$ & 0.0162 \\
$\mathrm{FP}(-1)$ & -0.514 & $-3.65^{*}$ & 0.0020 \\
$\mathrm{MS}(-1)$ & 0.378 & $4.24^{*}$ & 0.0006 \\
$\mathrm{SUB}(-1)$ & -0.024 & $-2.38^{* *}$ & 0.0293 \\
$\mathrm{FC}(-1)$ & -0.104 & -1.15 & 0.2641 \\
$\mathrm{WFP}(-1)$ & 0.273 & $5.46^{*}$ & 0.0000 \\
$\mathrm{PCI}(-1)$ & -0.295 & $-2.20^{* *}$ & 0.0416 \\
\hline$R^{2}=0.83$, & $\bar{R}^{2}=0.75$, & & \\
$\sum \varepsilon_{t}^{2}=0.0062$, & $A I C=-4.80$, & $S B C=-4.32$ \\
\hline Diagnostic tests & \multicolumn{5}{r}{ Heteroscedasticity: $\mathrm{F}=0.94[0.52]$} \\
\hline
\end{tabular}

Note: Asterisks * and ${ }^{* *}$ indicate significance at 1 and 5 percent, respectively. Source: Authors' estimates.

The redundant variables test (Table 4$)\left(\beta_{1}=\beta_{2}=\beta_{3}=\beta_{4}=\beta_{5}=\beta_{6}=0\right)$ rejects the null hypothesis that the variables have no power. Thus, they are

\footnotetext{
${ }^{4}$ Energy prices were initially part of the equation but were later dropped since they proved statistically insignificant, and the GTS model does not allow insignificant variables to be part of the model. Energy prices are not, therefore, among the determinants of food prices in Pakistan in our model.
} 
significantly different from 0 , which implies that there may be a long-run relationship among them.

Table 4: Redundant Variables

\begin{tabular}{lccc}
\hline Redundant variables: $\mathrm{FP}(-1), \mathrm{SUB}(-1), \mathrm{PCI}(-1), \mathrm{TP}(-1), \mathrm{M} 2(-1), \mathrm{LWF}(-1)$ \\
F-statistic & 22.71938 & Probability & $0.000000^{*}$ \\
Log likelihood ratio & 59.38082 & Probability & $0.000000^{*}$ \\
\hline
\end{tabular}

Note: Asterisk * indicates significance at 1 percent.

Source: Authors' estimates.

Table 5 shows normalized cointegrating vectors (long-run coefficients). We normalize the coefficients of lagged-level variables by dividing the coefficient of FP (assuming all the other coefficients are equal to 0 ) and obtaining the long-run elasticities. The results show that the subsidy variable is negatively associated with food prices. ${ }^{5}$ However its coefficient is too small to have a significant role in the long run; the implication is that a 100 percent increase in subsidies reduces food prices by 5 percent. Surprisingly, per capita income is negatively associated with food prices. The coefficient shows that a 1 percent increase in per capita income leads to a decline in food prices by 0.57 percent.

Table 5: Normalized Cointegrating Vectors

\begin{tabular}{lcc}
\hline Variable & Coefficient & t-value \\
\hline FP(-1) & 1.00 & \\
MS $(-1)$ & -0.74 & $-4.24^{*}$ \\
SUB $(-1)$ & 0.05 & $2.38^{* *}$ \\
FC $(-1)$ & 0.20 & 1.15 \\
WFP(-1) & -0.53 & $-5.46^{*}$ \\
PCI $(-1)$ & 0.57 & $2.20^{* *}$ \\
\hline
\end{tabular}

Note: Asterisks ${ }^{*}$ and ${ }^{* *}$ indicate significance at 1 and 5 percent, respectively.

Source: Authors' estimates.

Food crop production is used to capture the structural and cyclical impact on food prices. Over time, an increase in food crops increases the total supply of food crops, thus reducing food prices and vice versa. The negative sign of food crop variable shows the overall structural effect of a decrease in production leads to an increase in prices and vice versa.

${ }^{5}$ The equation is: $\varepsilon_{t}=f p_{t-1}+\beta_{2} S U B_{t-1}+\beta_{3} P C I_{t-1}+\beta_{4} Y_{t-1}+\beta_{5} m s_{t-1}+\beta_{6} w f p_{t-1}$ 
However, it is not statistically significant and, therefore, not a significant determinant of food prices in the long run.

Money supply appears to be the most significant variable determining the variation in food prices. Its coefficient is 0.74 , which implies that a 1 percent increase in money supply leads to a 0.74 percent increase in food prices. World food prices, the only international variable in our analysis, are positively associated with food prices. Its coefficient implies that a 1 percent increase in world food prices leads to a 0.53 percent increase in domestic food prices in the long run, which is quite high.

Next, we generate the residual of the equation and check its stationarity. If it is integrated of order zero, then it satisfies another condition of the presence of cointegration among the variables. The ADF, PP, and KPSS tests show that the residual is level stationary. ${ }^{6}$

We then proceed to check the error correction in the dependent variable. The error correction model is represented by

$$
\begin{aligned}
& \Delta f p_{t}=\beta_{0}+\sum_{i=1}^{n} \beta_{8} \Delta S U B_{t-i}+\sum_{i=1}^{n} \beta_{9} \Delta P C I_{t-i}+\sum_{i=1}^{n} \beta_{10} \Delta Y_{t-i}+\sum_{i=1}^{n} \beta_{11} \Delta m s_{t-i} \\
& +\sum_{i=1}^{n} \beta_{12} \Delta w f p_{t-i}+\lambda E C_{t-1}+\varepsilon_{2 t}
\end{aligned}
$$

where $\lambda$ represents the speed of adjustment and EC is the residual term obtained from the ARDL model.

Table 6 gives the results of the error correction model. Here, we use one less lag than in the ARDL approach (see, for example, S. Khan \& Khan, 2007), i.e., we use two lag differences. Applying the GTS methodology yields better results.

${ }^{6} \mathrm{ADF}=-2.07 * *$ (significant at $5 \%$ significance level), $\mathrm{PP}=-3.66 *$ (significant at $1 \%$ significance level), KPSS $=0.12$. 
Table 6: Results of Short-Run Dynamics (Error Correction Model)

\begin{tabular}{lcrl}
\hline \multicolumn{1}{c}{ Coefficient } & Coefficient & t-statistic & Prob. \\
\hline $\mathrm{EC}(-1)$ & -0.376110 & -10.248400 & $0.0000^{*}$ \\
$\mathrm{D}(\mathrm{MS}(-1))$ & 0.173448 & 3.293961 & $0.0033^{*}$ \\
$\mathrm{D}(\mathrm{PCI}(-1))$ & -0.744930 & -4.797430 & $0.0001^{*}$ \\
$\mathrm{D}(\mathrm{FP}(-2))$ & 0.509757 & 9.253716 & $0.0000^{*}$ \\
$\mathrm{D}(\mathrm{SUB}(-2))$ & -0.006180 & -2.750190 & $0.0117^{*}$ \\
$\mathrm{D}(\mathrm{PCI}(-2))$ & -0.333750 & -2.315980 & $0.0303^{*}$ \\
$\mathrm{D}(\mathrm{FC}(-2))$ & 0.065018 & 1.597895 & 0.1243 \\
\hline$R^{2}=0.876944$, & $\bar{R}^{2}=0.843383$, & \\
$\sum \varepsilon_{t}^{2}=0.004699$, & $A I C=-5.407054, \quad S B C=-5.077017$ \\
\hline
\end{tabular}

Note: Asterisk * indicates significance at 1 percent.

Source: Authors' estimates.

The overall result indicates the significant presence of error correction in the equation. Its negative sign implies that, whenever there is disequilibrium, food prices adjust toward equilibrium to restore it as market forces are in operation. The estimated value of $E C_{t-1}(0.376)$ indicates the speed of adjustment toward long-run equilibrium in response to disequilibrium, which is due to short-run shocks of the previous period-a rate of 37.6 percent. Since we have annual data, we assume it takes almost three years to restore complete equilibrium.

Money supply has a positive sign and is significant, indicating that it plays an important role in raising food prices in the short run. Per capita income has a negative impact on food prices even in the short run. Subsidies are effective and have a negative role in the second period in determining prices, which show that they serve to reduce food prices. Farmers are encouraged to grow more of that crop for which the government has announced a support price. Thus, subsidies create greater supply in the market, which helps reduce food prices.

\section{Stability Test}

In this section, we perform two tests on the ARDL model: (i) a cumulative sum (CUSUM) test and (ii) a CUSUM-of-squares test. Both will verify the stability of our estimates. 
The CUSUM test is based on the cumulative sum of the recursive residuals, and measures parameter instability within a 5 percent range. A value beyond this range indicates that the estimation is not stable. Figure 7 illustrates the results of the CUSUM test, which show that our estimates are stable.

Figure 7: Results of CUSUM Test for Stability of Estimates

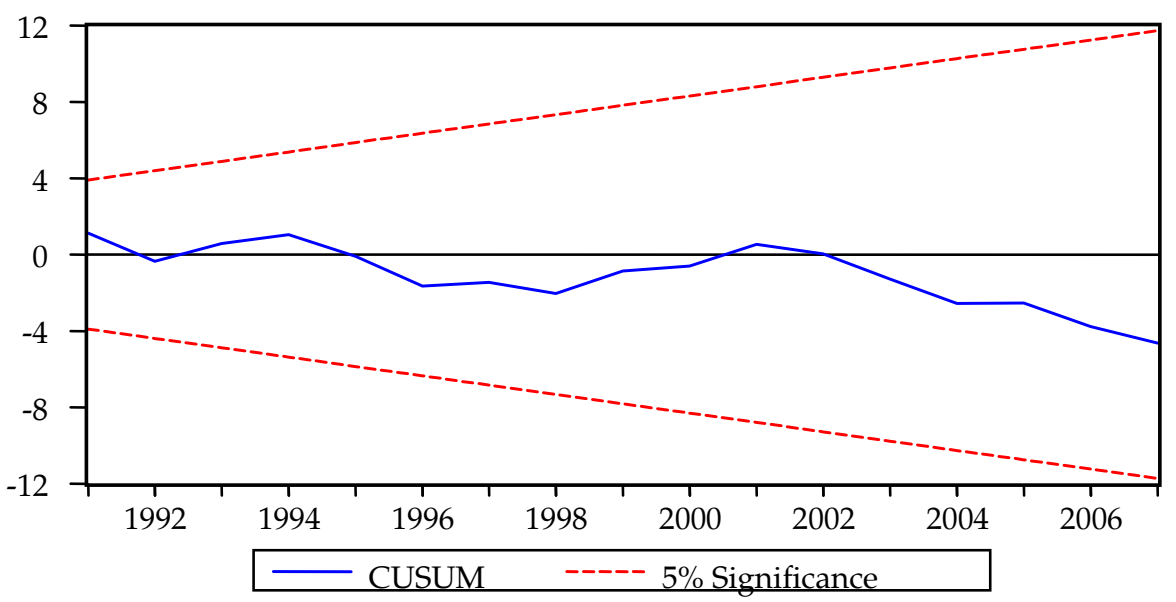

Source: Authors' calculations.

The CUSUM-of-squares test is performed on the squares of the residuals. Similar to the CUSUM test, this test measures parameter instability within the given range, and indicates whether or not the variance of the residuals is stable. Figure 8 shows that the cumulative sum of squares is within the given range, implying that our estimates also pass the second stability test. 
Figure 8: Results of CUSUM-of-Squares Test for Stability of Estimates

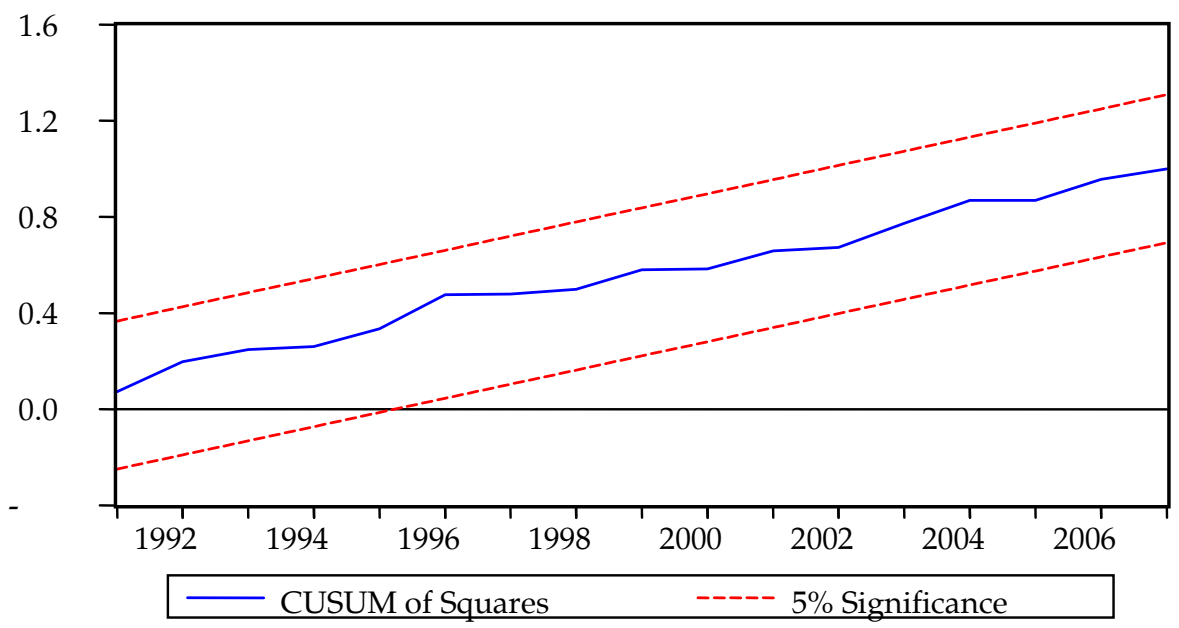

Source: Authors' calculations.

\section{Conclusion}

Over the last few years, the problem of increasing food prices both in Pakistan and globally has become a severe one. The predicament is not new, and the world has witnessed similar situations since the early 1970s. While there may be different reasons for the recent increase in prices, we have followed a relatively basic economic approach and developed a model including per capita income, agricultural output, agricultural subsidies, money supply, and world food prices as key determinants of food prices in Pakistan.

Our study leads us to conclude that the most significant variable affecting food prices in both the long- and short run is money supply. Agricultural subsidies help reduce food prices in the long run but their impact is very small. In the absence of imports, an increase in world food prices pressurizes the domestic market, causing a rise in domestic food prices. If, however, world food prices increase and we need to import food crops, we may generate imported inflation. The negative association of per capita income and food prices may imply Engle aggregation, i.e., that the percentage of expenditures on food items declines with an increase in income.

This, however, is the study's paradox: Food crop production does not appear to have an immediate effect on food prices, implying that 
movements in food prices follow factors other than the current production of domestic food crops more significantly. It is possible that the production of food crops follows their price in previous years and certain other factors, and not the other way around-this could be an area for further research. Changes in production over time are also not a major determinant of food prices. While there may be popular debate on energy prices and their impact on inflation, we do not find energy prices to be a key determinant of food prices. An important conclusion of the study is that food prices restore equilibrium when the system is in disequilibrium, but that it can take three years to do so.

We have not touched on the political economy of price increases, e.g., on issues such as smuggling and untimely exports followed by imports at higher prices - these are among the limitations of this study. 


\section{References}

Abdullah, M., \& Kalim, R. (2011, March). Determinants of food price inflation in Pakistan. Paper presented at the $1^{\text {st }}$ International Conference on Business Management, University of Management and Technology, Lahore, Pakistan.

Asian Development Bank. (2008). Food prices and inflation in developing Asia: Is poverty reduction coming to an end? Manila, the Philippines: Author. Retrieved from (http://www.adb.org/sites/default/files/Food-Prices-Inflation.pdf).

Capehart, T., \& Richardson, J. (2008, April). Food price inflation: Causes and impacts (Congressional Research Service Report for Congress). Washington, DC: Library of Congress. Retrieved from (http://fpc.state.gov/documents/organization/104281.pdf).

Chaudhry, T. T., \& Chaudhry, A. A. (2008). The effects of rising food and fuel costs on poverty in Pakistan [Special edition]. Lahore Journal of Economics, 117-138.

Eckstein, A., \& Heien, D. (1978). The 1973 food price inflation. American Journal of Agricultural Economics, 60(2), 186-196.

Gómez. J. G. (2008). Emerging Asia and international food inflation. Borradores de Economía, 512, 1-11.

Government of Pakistan. (n.d.). Agricultural statistics of Pakistan [Various issues]. Islamabad: Ministry of Food, Agriculture and Livestock.

Government of Pakistan. (n.d.). Federal budget: Budget in brief [Various issues]. Islamabad: Finance Division.

Government of Pakistan. (n.d.). Pakistan economic survey [Various issues]. Islamabad: Ministry of Finance.

Haque, N., \& Qayyum, A. (2006). Inflation everywhere is a monetary phenomenon: An introductory note. Pakistan Development Review, 45(2), 179-183.

International Monetary Fund Statistics Department. (2008). International financial statistics. Washington, DC: Author. 
Janjua, A. (2005), Money supply, inflation and economic growth: Issues in monetary management in Pakistan [Special edition]. Lahore Journal of Economics, 73-106.

Kemal, M. A. (2006). Is inflation in Pakistan a monetary phenomenon? Pakistan Development Review, 45(2), 213-220.

Khan, A. H., \& Qasim, M. A. (1996). Inflation in Pakistan revisited. Pakistan Development Review, 35(4, Pt. II), 747-759.

Khan, M. A., Qayyum, A., \& Sheikh, S. A. (2005, December). Financial development and economic growth: The case of Pakistan. Paper presented at the 21st Annual General Meeting and Conference of the Pakistan Society of Development Economists, Islamabad, Pakistan.

Khan, R. E. A., \& Gill, A. R. (2007). Impact of supply of money on food and general price indices: A case of Pakistan. IUB Journal of Social Sciences and Humanities, 5(2), 125-143.

Khan, S., \& Khan, M. A. (2007). What determines private investment? The case of Pakistan (Working Paper No. 36). Islamabad: Pakistan Institute of Development Economics.

Kwiatkowski, D., Phillips, P. C. B., Schmidt, P., \& Shin, Y. (1992). Testing the null hypothesis of stationarity against the alternative of a unit root. Journal of Econometrics, 54, 159-178.

Lamm, R. M., Jr., \& Westcott, P. C. (1981). The effects of changing input costs on food prices. American Journal of Agricultural Economics, 63(2), 187-196.

Lapp, J. S. (1990). Relative agricultural prices and monetary policy. American Journal of Agricultural Economics, 72(3), 622-630.

Liew, V. K.-S. (2004). Which lag length selection criteria should we employ? Economics Bulletin, 3(33), 1-9.

Mushtaq, K., Ghafoor, A., Abedullah, \& Ahmad, F. (2011). Impact of monetary and macroeconomic factors on wheat prices in Pakistan: Implications for food security. Lahore Journal of Economics, 16(1), 95-110. 
Naim, M. (2008, June 16). The global food fight. Foreign Policy, May-June. Retrieved from

(http://www.foreignpolicy.com/articles/2008/06/16/the_global_food_fight)

Pesaran, M. H., \& Shin, Y. (1997). An autoregressive distributed lag modeling approach to cointegration analysis. Mimeo, University of Cambridge, United Kingdom. Retrieved from (http://www.econ.cam.ac.uk/faculty/pesaran/ardl.pdf).

Political Risk Services Group. (n.d.). International country risk guide. East Syracuse, NY: Author.

Trostle, R. (2008). Global agricultural supply and demand: Factors contributing to the recent increase in food commodity prices. Washington, DC: United States Department of Agriculture.

United Nations Inter Agency Assessment Mission. (2008). High food prices in Pakistan: Impact assessment and the way forward. Islamabad, Pakistan: Author.

United States Department of Agriculture. Foreign Agricultural Service. (2008). Production, supply and distribution online. Retrieved from (http://www.fas.usda.gov/psdonline). 